\title{
Visual Harmony of Engineering Structures in a Mountain Stream
}

\author{
Jinn-Chyi Chen ${ }^{1}$, Chia-Ling Huang ${ }^{2}$, Su-Chin Chen ${ }^{2,3, *(D)}$ and Samkele S. Tfwala ${ }^{4}$ \\ 1 Department of Hydraulic Engineering, Fujian College of Water Conservancy and Electric Power, \\ Yongan 366000, China; chenjinnchyi@gmail.com \\ 2 Department of Soil and Water Conservation, National Chung Hsing University, Taichung 40227, Taiwan; \\ judy820517@gmail.com \\ 3 Innovation and Development Center of Sustainable Agriculture, National Chung Hsing University, \\ Taichung 40227, Taiwan \\ 4 Department of Geography, Environmental Science and Planning, University of Eswatini, Matsapha M202, \\ Eswatini; sstfwala@uniswa.sz \\ * Correspondence: scchen@nchu.edu.tw
}

Citation: Chen, J.-C.; Huang, C.-L.; Chen, S.-C.; Tfwala, S.S. Visual Harmony of Engineering Structures in a Mountain Stream. Water 2021, 13 3324. https://doi.org/10.3390/ w13233324

Academic Editor: Tammo Steenhuis

Received: 15 October 2021

Accepted: 19 November 2021

Published: 23 November 2021

Publisher's Note: MDPI stays neutral with regard to jurisdictional claims in published maps and institutional affiliations.

Copyright: (c) 2021 by the authors. Licensee MDPI, Basel, Switzerland. This article is an open access article distributed under the terms and conditions of the Creative Commons Attribution (CC BY) license (https:// creativecommons.org/licenses/by/ $4.0 /)$.

\begin{abstract}
This study uses the cognitive factor of "visual harmony" to assess the visual quality of stream engineering in a mountainous region. Images of engineering structures such as revetments and submerged dams in the mountain streams of Taiwan were collected. Three image groups with different structures invaded by vegetation were used for a questionnaire survey, which yielded 154 valid samples. We used statistical analysis to develop a model of visual harmony $H$ with respect to the percentage of visible greenery $G_{R}$, that is, the perceived curve of vegetation change. A comparison of our data with the literature determined the upper and lower bound curves of the relationship between $H$ and $G_{R}$. We found that the physical elements of "softscape" and "hardscape"—namely, percentage of visible water $W_{R}$, visible structure $I_{R}$, and visible natural material on the structure $N_{R}$-affected this relationship. Results show that $H$ is equivalent to visual preference $P$, and both can be improved by better green visibility (increasing $G_{R}$ and $G_{R}<50 \%$ ), avoiding low water visibility $\left(W_{R}<10 \%\right)$, or increasing the amount of visible natural material $\left(N_{R}>0.9\right)$. High visibility of the structures $\left(I_{R}>0.3\right)$ may decrease $H$ and $P$. We ultimately propose a visual harmony or preference model concerning a combined physical indicator that comprises $G_{R}, W_{R}, I_{R}$ and $N_{R}$. Results of this study could be helpful to improve or access the aesthetics of stream engineering design.
\end{abstract}

Keywords: harmony; preference; cognitive factors; physical elements; questionnaire survey

\section{Introduction}

The concept of harmony is an essential focus of attention in engineering, management, art, and design. One such example is the harmony sought to balance safety (for humans), ecology, and landscape in ecological engineering within the more extensive study of soil and water conservation [1]. Other examples include human-water harmony when developing evaluation models in hydraulic engineering and water resources management [2-4], harmony in human-river encounter sites [5], harmony in ecosystem service [6], and many studies concerns about colour harmony in colour combinations [7,8], art and design [9], and urban spaces $[10,11]$.

\subsection{Visual Harmony}

There are many definitions of harmony in different study fields. In colour harmony, key words associated with harmony include "completeness", "complementary/analogous", "order", "balance", "unambiguous", and "pleasing" [12,13]. "Harmony" and "preference" are often used interchangeably and are regarded equivalent in early previous analyses [13]. However, some studies showed that two terms of "preference" for and "harmony" of colour combinations may produce confusing results $[8,13]$. 
Within the study of visual landscape, harmony reflects unity and balance, or the pleasant "arrangement" of landscape attributes [14]. It is closely related to coherence [15] or unity. Harmony, coherence and unity are interchangeable terms [16]. Harmony or coherence has been associated with water features [16-18] and land-use suitability $[16,19,20]$. It is an important cognitive indicator [21] and may be associated with landscape physical elements. Thus, harmony was selected as an indicator in this work to investigate changes of proportions of water and vegetation, and property of engineering structures (scale and texture) in mountainous stream landscape. Visual harmony in this paper describes the perceived balance of landscape attributes to form a coherent, unified whole. Visual preference focuses on people's preference or aversion to the landscape. Visual preference and harmony were regarded as different terms in this work. They are important cognitive processes in aesthetic assessment.

\subsection{Aesthetic Assessments of Rivers}

Defining aesthetics has been addressed by [13]. Ideally, it refers to the study of human minds and emotions in relation to the sense of beauty. However, aesthetics, such as we usually talk about (the beauty or ugliness of an object or a scene), is subjective, and it depends on personal aesthetic experiences. Thus, the terms public perception or preference were generally used by researchers to investigate aesthetic quality or aesthetic assessment. Visual preferences reflect the degree to which people experience it as beautiful (or ugly). It is a cognitive process and a product of perception that should be considered in studies involving people's aesthetic judgments and selectivity, including perceptions of the environment [22]. Research on the aesthetic assessments or visual quality of rivers has often been addressed in many studies, such as river restoration measures [23], river with recreation infrastructures [24,25], wood in rivers [26,27], water quality [28], and engineering structures in mountainous streams [21,29]. There are a few soils and water conservation studies on the visual quality of sediment control structures in mountain streams written from the perspective of perception [21,29]. The goal of stream engineering design is safety and functionality. Yet, with more excellent environmental quality and growing public interest in landscape beauty, visual preference and visual harmony has become a part of engineering design. Chen et al. [21] proposed a model of visual preference associated with cognitive factors, such as harmony, naturalness, vividness, and closeness, in sediment control structure in mountainous streams. The property of softscape elements, i.e., the visible body of water and vegetation, associated with cognitive indicators were also presented. However, the model was developed based on cognitive factors. Studies on how visual harmony $(H)$ and visual preference $(P)$ are affected by the structure's texture and its proportion (namely, hardscape elements in this work), and how they are associated with softscape elements, are still lacking. Particularly, an evaluation model using softscape and hardscape elements may be more interesting to a hydraulic or landscape designer and manager than applying cognitive factors. Softscape and hardscape are direct and the designer or manager can try to adjust the physical environment elements to prompt aesthetic quality.

\subsection{Objectives of This Study}

Engineering structures allow for self-design by nature and considering their harmony with nature is a design norm. For examples, a stone revetment, groundsill, or dam with stone lining has voids between stones at the surface that allow vegetation to invade, increasing greenery and, thus, visual beauty [30]. However, overgrown greenery can destroy the harmony of the stream's landscape and sediment control structures [21]. Such invasion of vegetation in stone revetments and other sediment control structures is well documented in the literature [21,29]. However, a lack of study determines the impact curve nor evaluation model of visual harmony nor preference with respect to visual greenery for application. If such a model were established, the visual quality of engineering design, management, and maintenance could be improved. There also exists some evidence of an 
evaluation model of visual preference that discusses the influence of softscapes (water and greenery) on cognitive factors [21], but it ignores hardscapes, despite such elements being vital in design.

Visual harmony is a cognitive process resulting from a sense of visual order, unify, and coherence between and among the landform, water, vegetation, or structures visible. It allows the human eye to connect the "softscapes" and "hardscapes" easily-that is, physical elements-through engineering design. Harmony may increase scenic beauty and public acceptance $[21,22,29]$ and it should be seriously considered in assessment visual quality of engineering structures in mountain stream [21]. This paper focuses on visual harmony of engineering structures in a mountain stream, particularly vegetation invading engineering structures. Emphasis is on how visual harmony and preference are affected by vegetation after engineering structures were completed, and how to develop a model of visual harmony with respect to the physical elements, such as the percentage of visible water, visible structure, and visible natural material on the structure. The visual harmony influenced by the proportions of water, vegetation, and engineering structures, and structure texture were studied. Visual harmony associated with preference is also presented. Understanding the visual harmony of physical elements may improve the aesthetics of stream engineering design and may help scholars develop a model for assessing visual quality.

\section{Overview of Gungfunnan, Chotengkeng, and Tungsikun Creeks}

Taiwan is a mountainous island. Hills cover seventy percent of its total landmass. The rivers in mountainous regions have steep slopes and flow at rapid velocities, necessitating the need for sediment control engineering to stabilize the streambed and prevent hazards related to sediment and water flow. In 2001, the Soil and Water Conservation Bureau (SWCB) in Taiwan began to promote innovation in ecological engineering [1]. Currently, the typical engineering structures in Taiwan include stone revetments, groundsills, submerged dams, and check dams.

We chose a location upstream of the Gungfunnan creek in Yilan Country and Chotengkeng creek in Taichung City in the Taiwanese mountains (see Figure 1 and Table 1). The Gungfunnan creek has a watershed area of 866 ha and a main stream length of $5.5 \mathrm{~km}$. In 1997, Typhoon Sinlaku caused landslides and floods in the watershed, leading to massive sediment deposition downstream. The Chotengkeng creek has a watershed area of 1320 ha and a main stream length of $8 \mathrm{~km}$. It experienced floods, landslides, and massive debris flow during Typhoon Mindulle in July 2004. Subsequently, the SWCB has constructed a series of stone groundsills, stone revetments, and submerged dams in the two creeks to control sediment flow. The stones for such ecological structures were sourced from on-site streambeds or stream sides to utilise the natural resource and increase the flow area of the creeks. Groundsills can stabilize streambeds and the toe of the slopes, but they also tend to raise the streambed, leading to vegetation invasion. Stone revetments mainly protect the toe of the streambank to avoid erosion. In these structures, the voids between the stones allow vegetation to proliferate compared with concrete revetments.

Figure 1 shows three observation points, namely, P1, P2, and P3, and their viewing scenes in the study area. The viewing scenes at P1 and P2 were taken upstream of Gungfunnan creek. Figure $1 b, c$ show the stone revetment, groundsill works, and submerged dam. P3 (see Figure 1d) was taken from Chung-Ho bridge downstream of Chotengkeng creek, showing a declined groundsill with stone lining. Figure $1 \mathrm{~b}-\mathrm{d}$ were collected from the SWCB in the early stages after engineering works were completed. All images were captured from either river banks or on a bridge. They were easily viewable with the naked eye such that aerial, long-range, and panoramic shots were not necessary. These images were used to investigate the changes in vegetation on the riversides and riverbeds. 

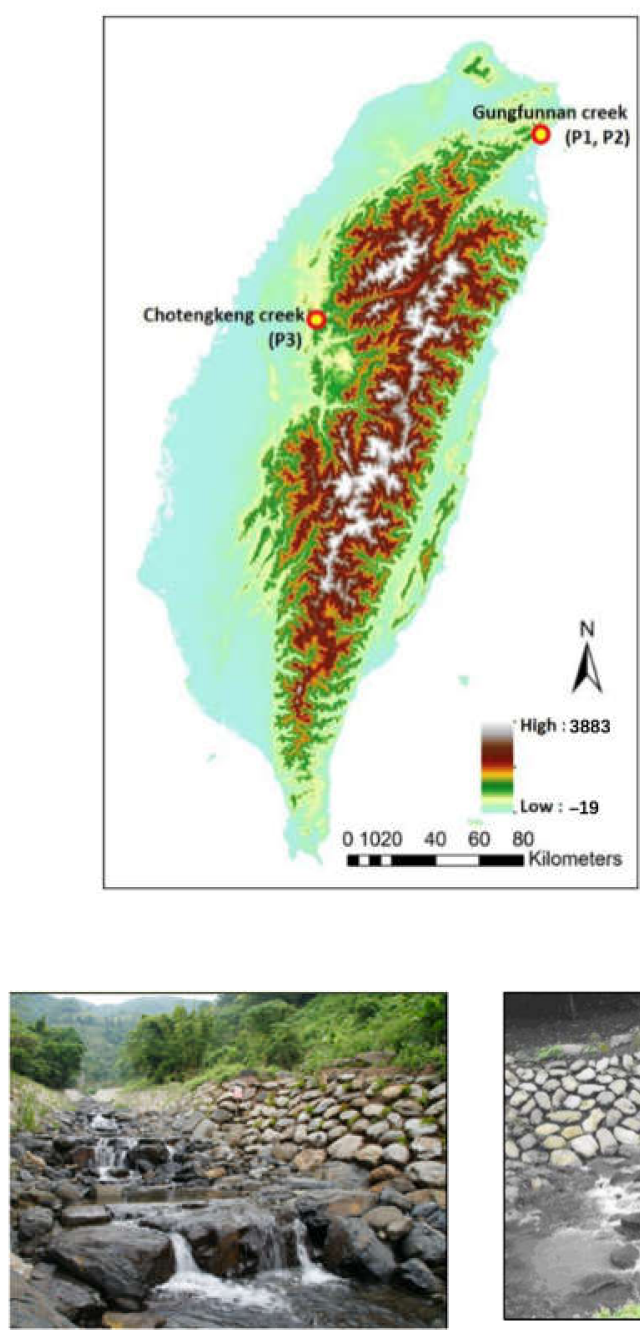

(b)

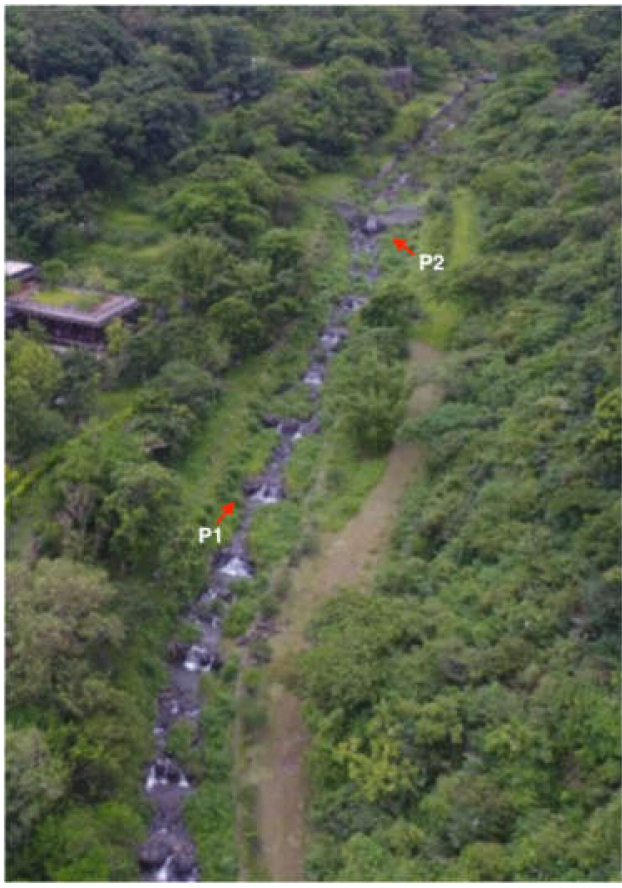

Gungfunnan creek, top view (July 2018) (a)

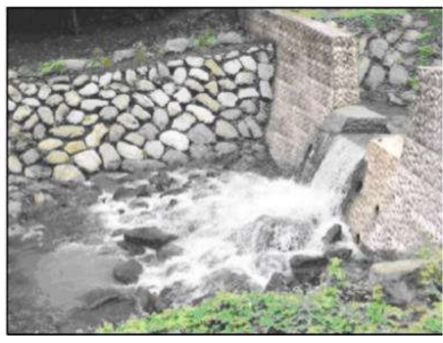

(c)

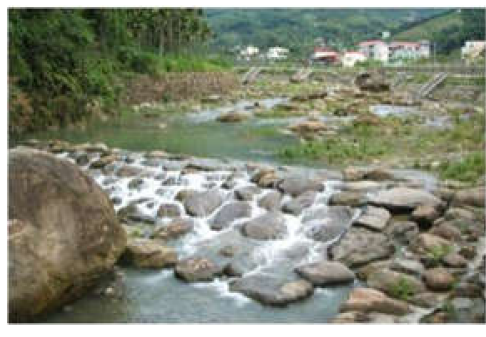

(d)

Figure 1. Study area and observation sites in the Gungfunnan creek in Yilan Country and Chotengkeng creek in Taichung city, Taiwan. Note. Figure 1b-d were collected from SWCB in the early stage after the engineering works were completed, and they were used to investigate the changes in vegetation on the riversides and riverbeds. (a) Maps showing the study area and observation sites P1, P2, and P3; (b) Viewing scene at P1(SWCB, November 2012); (c) Viewing scene at P2 (SWCB, September 2012); (d) Viewing scene at P3 (SWCB, September 2008).

Table 1. Watershed characteristics of Gungfunnan (upstream) and Chotengkeng creeks.

\begin{tabular}{|c|c|c|c|c|c|}
\hline Location & $\begin{array}{l}\text { Watershed } \\
\text { Area (ha) }\end{array}$ & $\begin{array}{l}\text { Mainstream } \\
\text { Length (km) }\end{array}$ & $\begin{array}{c}\text { Stream } \\
\text { Width }(\mathrm{m})\end{array}$ & Average Riverbed Slope & Engineering Structures \\
\hline Gungfunnan creek & 866 & 5.5 & $6-15$ & $\begin{array}{l}\text { Mainstream: } 7.07 \% \\
\text { Tributary: } 15-17 \%\end{array}$ & $\begin{array}{l}\text { Stone revetments, stone } \\
\text { groundsills, and } \\
\text { submerged dam }\end{array}$ \\
\hline Chotengkeng creek & 1320 & 8.0 & $10-20$ & $\begin{array}{l}\text { Mainstream: } 2.7 \% \text {; } \\
\text { Tributary: } 10-16 \%\end{array}$ & $\begin{array}{l}\text { Declined groundsill with } \\
\text { stone lining }\end{array}$ \\
\hline
\end{tabular}

\section{Methods}

First, field images were collected, followed by image processing. Secondly, the physical elements of each image were calculated. Thirdly, a questionnaire survey was conducted. Participants were asked to rate selected images for their visual preferences and visual harmony. The mean value of the visual preference and harmony in each image was 
determined through statistical analysis. Finally, a visual harmony and preference model that includes a combined physical indicator was proposed.

\subsection{Image Collection and Processing}

Images were simulated using Adobe ${ }^{\circledR}$ Photoshop ${ }^{\circledR}$ CC in 2015 version. All simulated images had the same background (sky, mountain, and water); and only the vegetation on the riverbed and riversides differed. Figure 2 shows the changes of the riverside landscape in the upstream section of Gungfunnan creek. Five images C1-1, C1-2 were collected from SWCB, C1-4 from field investigation, and C1-3 and C1-5 images from image processing, referred to as images $\mathrm{C} 1-2$ and/or $\mathrm{C} 1-4$. Image $\mathrm{C} 1-3$ simulates the vegetation invasion in the stage between November 2012 (Image C1-2) and July 2018 (Image C1-4). After engineering was completed, six years (Image C1-4), vegetation started to naturally invade riverbanks and riverbed, compared to Image C1-2. However, excessive vegetation on banks and riverbed increased flow resistance and led to overflow. Image C1-5, simulation based on C1-2 and C1-4 images, simulates vegetation removed from riverbed after July 2018 for management requirements. This followed the background of image C1-2, and merging the vegetation on river banks of image $\mathrm{C} 1-4$.

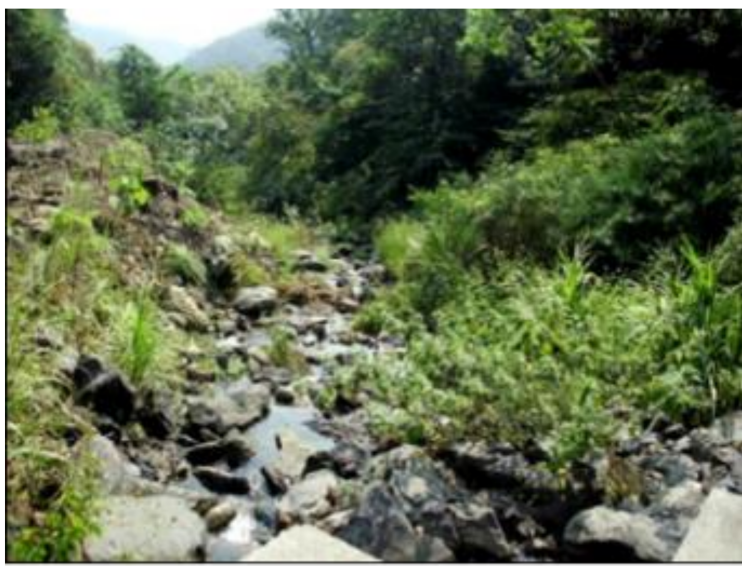

C1-1

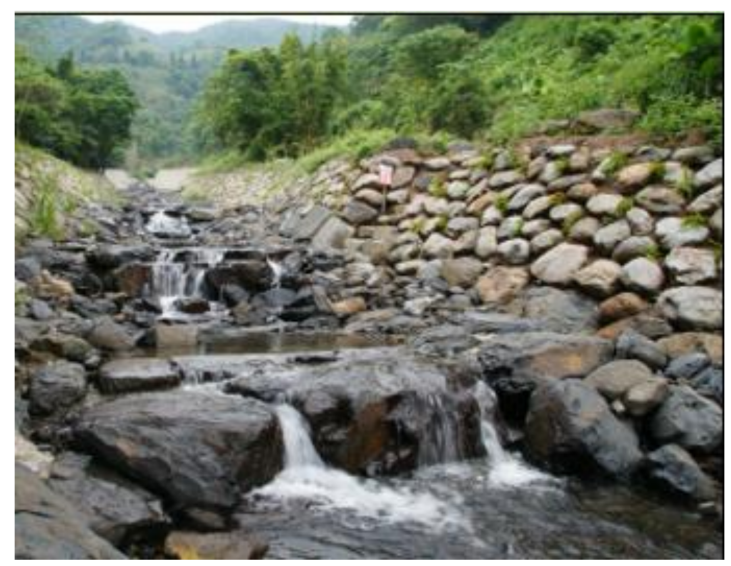

C1-2

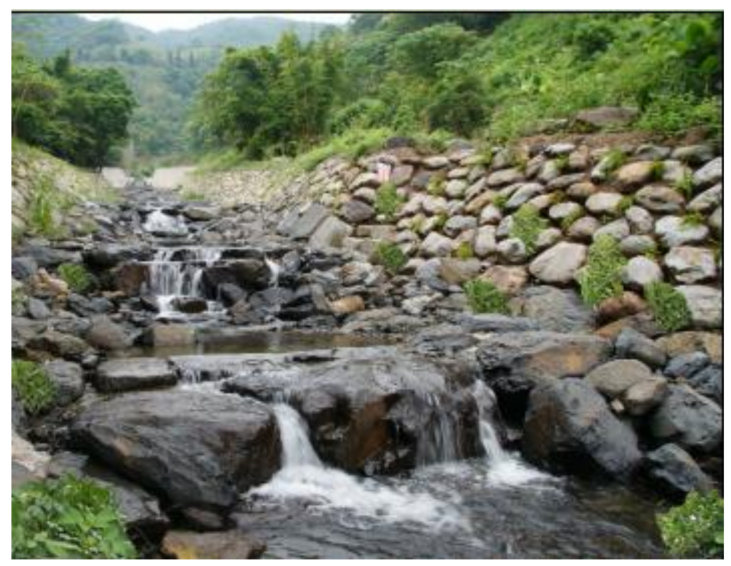

C1-3

Figure 2. Cont. 


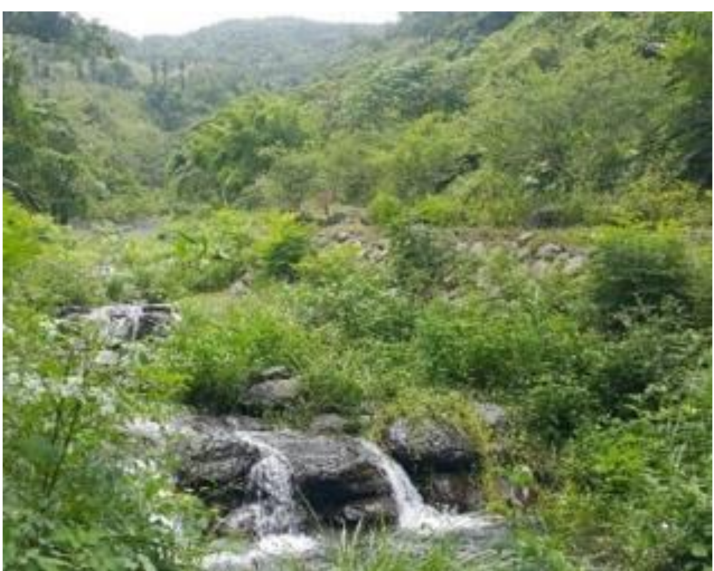

C1-4

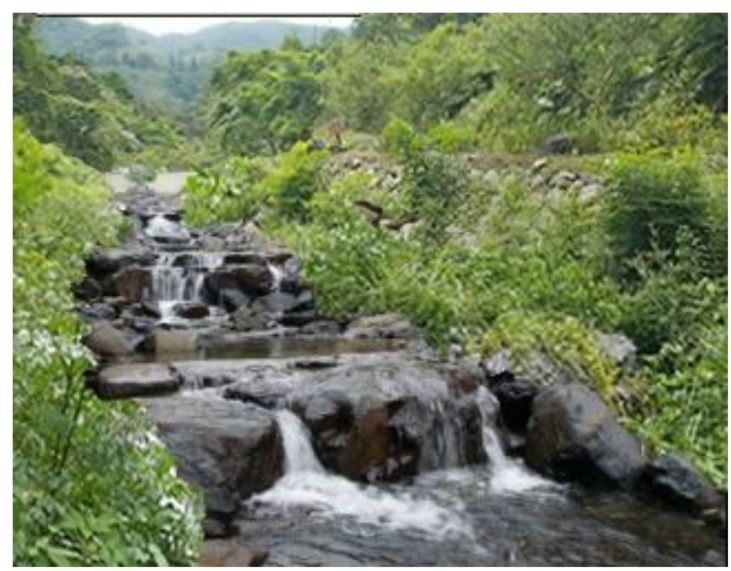

C1-5

Figure 2. Changes in the riverside landscape from engineering works, vegetation invasion, and human maintenance in the up-stream section of Gungfunnan creek. These images were collected between 2011 and 2018. The field images include the river landscape before engineering (C1-1) and after engineering treatment (C1-2 to $\mathrm{C} 1-4)$. Image $\mathrm{C} 1-3$ shows increasing vegetation after Image C1-2, and Image C1-5 shows no riverbed vegetation after Image C1-4. C1-1: Prior to engineering, with visible greenery, $G_{R}$, at $66 \%$ (SWCB, September 2011). C1-2: Early stage after the engineering complete, with visible greenery, $G_{R}$, at $24 \%$ (SWCB, November 2012). C1-3: Vegetation invasion, with visible greenery, $G_{R}$, at $31 \%$ (Simulation based on C1-2 and C1-4 images). C1-4: Vegetation invasion, with visible greenery, $G_{R}$, at 76\% (July 2018). C1-5: No riverbed vegetation, with visible greenery, $G_{R}$, at $60 \%$ (Simulation based on C1-2 and C1-4 images).

Figure 3 shows four images (C2-1, C2-2, C2-3, and C2-4) with different vegetation growing over the revetment in the upstream section of Gungfunnan creek. Image C2-1 were collected from SWCB in 2012 and Image C2-4 were taken from field investigation in 2018. Images $C 2-2$ and $C 2-3$ were generated by image processing to simulate the changes of vegetation invasion on revetment. The simulated vegetation elements referred to the real images of $\mathrm{C} 2-1$ and $\mathrm{C} 2-4$. All images in Figure 3 showed the early stage of complete engineering ( $C 2-1)$, and gradual invasion of vegetation after engineering ( $C 2-2$ to $C 2-4)$.

Figure 4 includes three images (C3-1, C3-2, and C3-3) showing changes in the riverbed vegetation at Chung-Ho bridge in the downstream section of Chotengkeng creek. Image C3-1 was collected from SWCB in 2008, and C3-2 and C3-3 images are from image processing. C3-3 is a merged image that combined the real vegetation on the riverbed from field investigation in 2018 and the background of Image C3-1. Twelve images (see Figures 2-4) were used to investigate the changes in vegetation.



C2-1

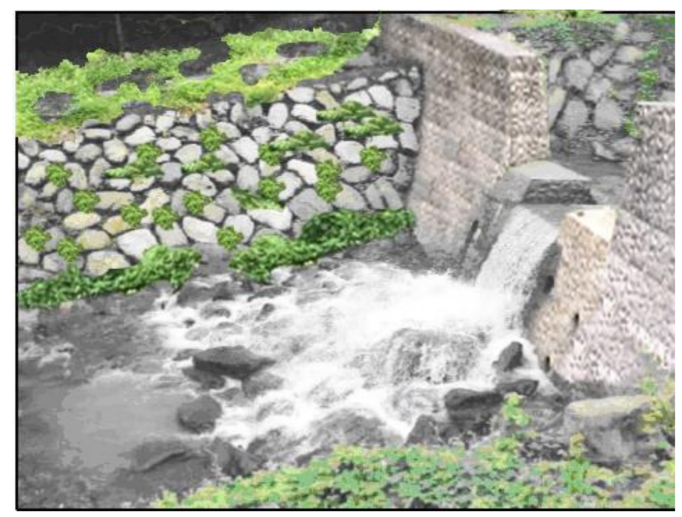

C2-2

Figure 3. Cont. 




C2-3

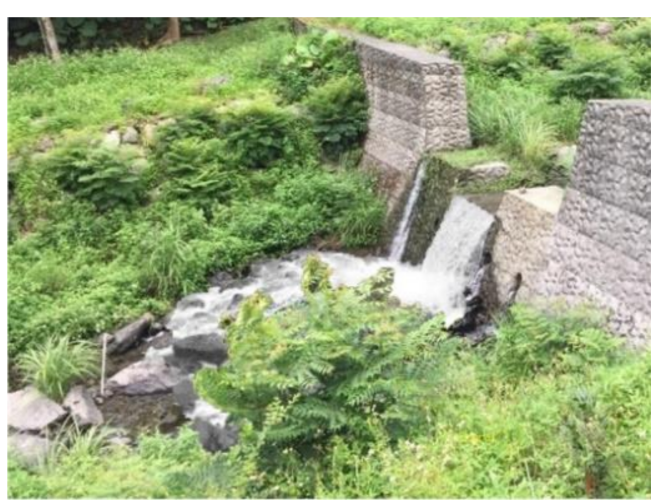

C2-4

Figure 3. Changes in the revetment vegetation in the upstream section of Gungfunnan creek. Showing the early stage of complete engineering (C2-1), and the gradual invasion of vegetation after engineering (C2-2 to C2-4). Images C2-1 and C2-4 were collected from the field, respectively from SWCB in 2012 and in 2018. Images C2-2 and C2-3 were generated by image processing to simulate the changes of vegetation invasion on the revetment. $C_{2}-1$ : Engineering complete, with visible greenery, $G_{R}$, at $8 \%$ (SWCB, September 2012). C2-2: Vegetation invasions on revetment, with visible greenery, $G_{R}$, at $25 \%$ (Simulation). C2-3: Vegetation invasions on revetment, with visible greenery, $G_{R}$, at $41 \%$ (Simulation). C2-4: Vegetation invasions on revetment, with visible greenery, $G_{R}$, at $60 \%$ (July 2018).

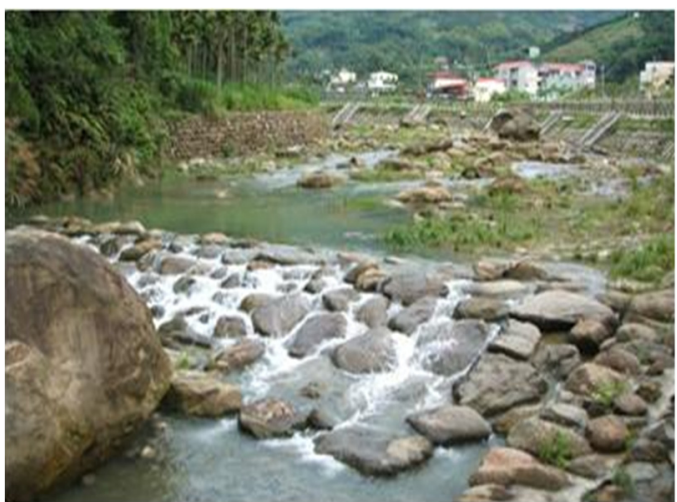

C3-1

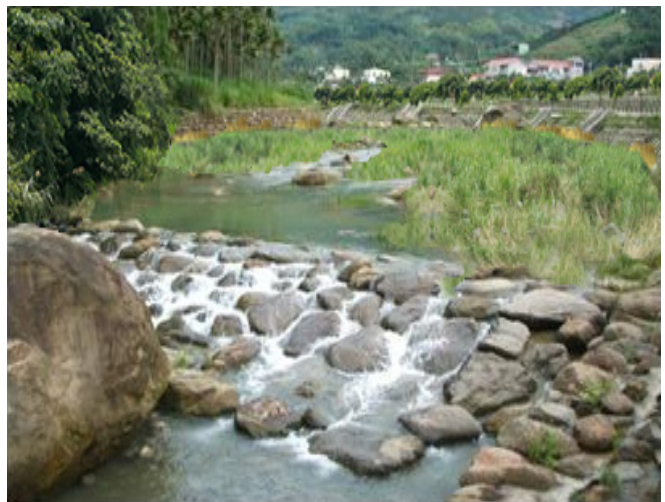

C3-2

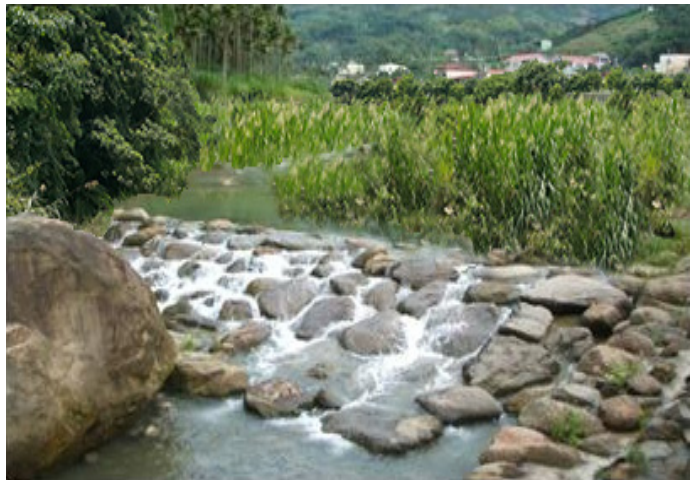

C3-3

Figure 4. Changes in the riverbed vegetation at Chung-Ho bridge, at the downstream section of Chotengkeng creek. Image C3-1 was collected SWCB in 2008, and C3-2 and C3-3 are from images processing. C3-3 is a merged image that combined the real vegetation on riverbed from field investigation in 2018 and the background of Image C3-1. C3-1: Engineering complete, with visible greenery, $G_{R}$, at 19\% (SWCB, September 2008). C3-2: Simulation based on Image C3-1, with visible greenery, $G_{R}$, at 30\%. C3-3: Merged image of Image C3-1 and field image on July 2018, with visible greenery, $G_{R}$, at $45 \%$. 


\subsection{Calculating the Physical Elements Using the Four Visible Indicators}

All images were adjusted to the dimension of $72.25 \times 54.19 \mathrm{~cm}(2048 \times 1536$ pixels $)$ in Adobe ${ }^{\circledR}$ Photoshop ${ }^{\circledR}$. Four visible indicators, namely, the percentages of visible greenery $\left(G_{R}\right)$, visible water $\left(W_{R}\right)$, visible structure $\left(I_{R}\right)$, and visible natural material on the structure $\left(N_{R}\right)$ in each image were determined as follows:

$$
\begin{aligned}
G_{R} & =G / T \\
W_{R} & =W / T \\
I_{R} & =I / T \\
N_{R} & =N / I
\end{aligned}
$$

In all equations, $T$ is the total number of pixels of an image. $G, W$, and $I$ are the numbers of pixels of green vegetation, water, and engineering facilities, respectively, in the image. Engineering facilities here refer to structures of stream engineering, such as dam, groundsill, and/or revetment. A few images contain part of the road. Visible natural material, $N$, is the number of pixels of natural material in the engineering facilities. The natural materials in an image are all from on-site stones or boulders. For each image, pixels of green vegetation, water, engineering facilities, and natural material were judged by the naked eye, and the number of pixels were determined in Adobe ${ }^{\circledR}$ Photoshop ${ }^{\circledR}$.

\subsection{Questionnaire Survey}

Visual preference is a cognitive process and a product of perception that is important for analysing people's aesthetic judgments and selectivity, including perceptions of the environment [22]. It is generally regarded as a critical index for evaluating the overall landscape quality accepted by the public. It can be affected by many cognitive factors, such as naturalness, harmony, openness or closeness, vividness, and complexity [31,32]. Visual preference positively correlates with harmony, naturalness, and vividness but negatively with openness or closeness for a landscape with sediment control structures in mountain streams. Among the four cognitive factors, visual harmony has the most substantial effect on visual preference [21]. Thus, we selected two cognitive factors, namely, visual harmony and visual preference in this study.

In the literature, questionnaire surveys are the most widely used for studying the visual perception of a landscape. An online questionnaire survey was accordingly distributed using cloud based SurveyCake to licensed engineers, academic researchers, consultant companies, and the general public through email and social media channels such as LINE, WeChat, and Facebook, who were then asked to further disseminate the questionnaire among their peers. Respondents provided their gender, age, and professional background under complete anonymity and rated their visual preferences and visual harmony for each image.

Twelve images were divided into three groups, C1, C2 and C3, as shown in Figures 2 and 4, and rated using a five-point Likert scale. That is, each image had five responses for visual preference or harmony. That is, each image had five responses for visual preference or harmony: "very high (1)" , "high (0.8)" , "normal (0.6)", "low (0.4)" and "very low $(0.2)$ ". For example, if the image scores 1 , the respondent's visual preference for it is very high, and a score of 0.2 means low preference. All questionnaire samples were divided into two groups: general public and experts. An expert in this work is defined as a person with a master's degree or career experience over two years in hydraulic engineering, civil engineering, soil and water conservation, or landscape architecture. There were 154 valid respondents: 67 for experts and 87 for the general public, $8 \%$ aged under 20 years, $71 \%$ aged $20-30$ years, $16 \%$ aged $30-40$ years, and $5 \%$ aged $30-40$ years. The scores on visual preference and visual harmony for each image were statistically analysed using Microsoft Excel and Golden Software Grapher ver 12. 


\subsection{Results Presentation}

There are 12 images with different degrees of visible greenery in the upstream section of Gungfunnan creek (groups $\mathrm{C} 1$ and $\mathrm{C} 2$ in Figures 2 and 3 showing the changes to the riverside and revetment), and in Chotengkeng creek (group C3 in Figure 4). All images were used for the questionnaire survey. The mean value of the visual preference and harmony was determined through statistical analysis of the scores of each image. Finally, we present our results as follows:

First, the visual quality of stream engineering, given the invasion of vegetation was investigated to determine the perceived curve of vegetation changes (VCC) based on the relationship between visual harmony (or preference) and visible greenery. Secondly, the observed data from this study were compared with previous data $[21,30,33]$, as summarized in Table 2, to determine if VCC is a reasonable measure in our study's context. Third, we discussed the relationship between visual harmony (or preference) and visible greenery, and their relationship with the softscape and hardscape (e.g., water and the textures of each structure). Finally, we proposed a visual harmony model that includes a combined physical indicator.

Table 2. Studies on visual quality of stream engineering in mountainous regions.

\begin{tabular}{|c|c|c|c|c|}
\hline Researchers & Perceived Factors & Source of Images & $\begin{array}{c}\text { Groups in } \\
\text { Questionnaire }\end{array}$ & Rates in Questionnaire \\
\hline $\begin{array}{l}\text { Ho et al. } \\
\text { [30] }\end{array}$ & $\begin{array}{l}\text { Visual preference } \\
\text { and naturalness }\end{array}$ & $\begin{array}{l}\text { Field images show changes to } \\
\text { stream landscape from vegetation } \\
\text { invasion on stone revetments in } \\
\text { the Nan-Shi-Ken stream, Northern } \\
\text { Taiwan; includes four images, } \\
\text { A-17 to A-20 as shown in } \\
\text { Figure A1, at a fixed site at } \\
\text { different times after the } \\
\text { stream remediation }\end{array}$ & $\begin{array}{l}\text { No specific } \\
\text { classification }\end{array}$ & $\begin{array}{l}\text { The values of visual preference } \\
\text { and naturalness were divided } \\
\text { into eight intervals from zero } \\
\text { to one }\end{array}$ \\
\hline Jiang [33] & $\begin{array}{l}\text { Visual preference, } \\
\text { naturalness, harmony, } \\
\text { closeness, vividness, } \\
\text { continuity, and mystery }\end{array}$ & $\begin{array}{l}\text { Changes to stream landscape from } \\
\text { vegetation invasion on riversides } \\
\text { in Northern Taiwan; includes four } \\
\text { images, A-21 to A-24 as shown in } \\
\text { Figure A1, at a fixed site using } \\
\text { image simulation }\end{array}$ & $\begin{array}{l}\text { No specific } \\
\text { classification }\end{array}$ & \multirow{2}{*}{$\begin{array}{l}\text { Five-point Likert scale from } 5 \\
\text { (highest) to } 1 \text { (lowest); the } \\
\text { scores are normalized (divided } \\
\text { by } 5 \text { ) to } 1,0.8,0.6,0.4 \text {, and } 0.2 \\
\text { in this study for comparison }\end{array}$} \\
\hline $\begin{array}{l}\text { Chen et al. } \\
\text { [21] }\end{array}$ & $\begin{array}{l}\text { Visual preference, } \\
\text { naturalness, harmony, } \\
\text { closeness, and vividness }\end{array}$ & $\begin{array}{l}\text { Sediment control structures } \\
\text { including revetments, grade } \\
\text { control structures, submerged } \\
\text { dams, and check dams constructed } \\
\text { by the Soil and Water } \\
\text { Conservation Bureau, Taiwan, in } \\
\text { mountain streams; includes } \\
\text { sixteen images, A-1 to A-16 as } \\
\text { shown in Figure A1, collected } \\
\text { from different sites }\end{array}$ & $\begin{array}{l}\text { Expert and } \\
\text { general public }\end{array}$ & \\
\hline
\end{tabular}

\section{Results and Discussions}

\subsection{Harmony}

Figure 5 shows the relationship between the harmony and percentage of visible greenery in the data for groups $\mathrm{C} 1, \mathrm{C} 2$, and C3. A comparison between the two samples from the general public and experts is presented. There are many data points overlapping among the groups, and the samples from the general public and experts are consistent for the relationship between visual harmony and visible greenery. Overall, visual harmony increases with the increase in visible greenery at the approximate value of $<40 \%$ but slightly decreases for $G_{R}>60 \%$. That is, it exhibits an opposite trend at a critical value of $G_{R}$. The 
approximate critical value of visible greenery may be between $40 \%$ and $60 \%$, consistent with previous studies [21,33], as shown in Figure 6. Optimal harmony can be achieved when visible greenery is between 0.4 and 0.6 .

As indicated by red and black circles, data from previous studies are more scattered than the current data, as indicated by red and black solid dots. This may be because most images collected from previous studies were taken from different locations and their characteristics are diverse, including different landforms and sediment control structures. Sixteen images, all from different locations and those with different scenes and engineering structures, were collected [21]. We studied only three locations and focused on changes to vegetation in the same image background.

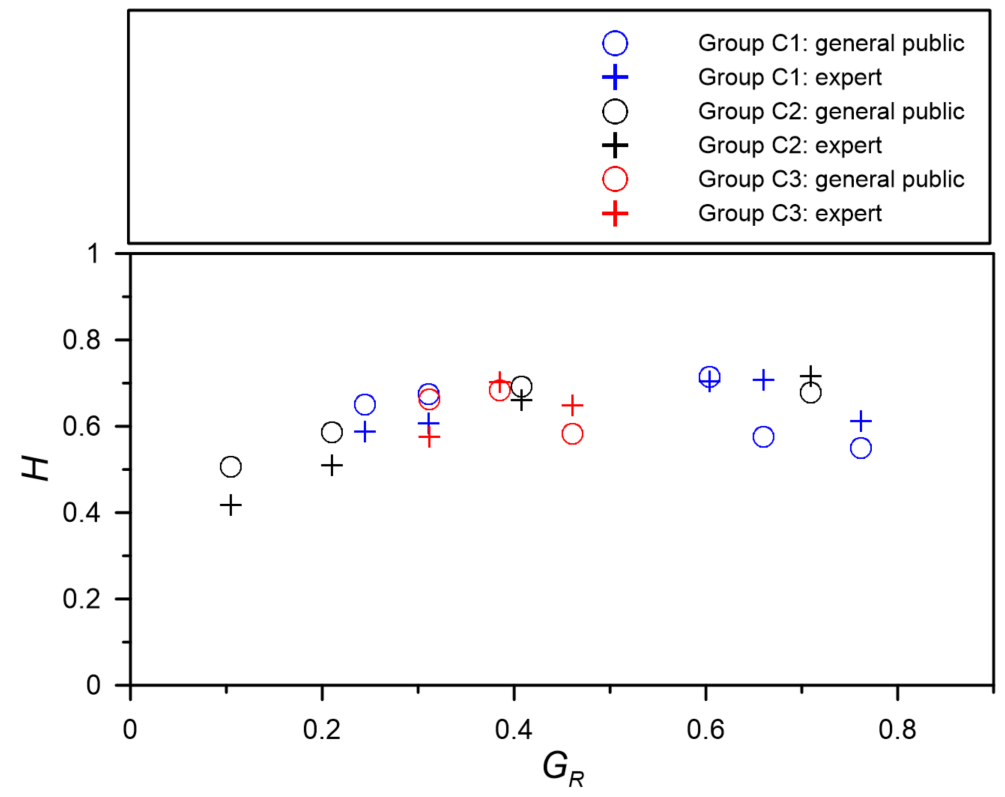

Figure 5. Relationship between the harmony $H$ and percentage of visible greenery $G_{R}$ in the current data for groups $\mathrm{C} 1, \mathrm{C} 2$, and $\mathrm{C} 3$, and comparison between the two samples for the general public and experts.

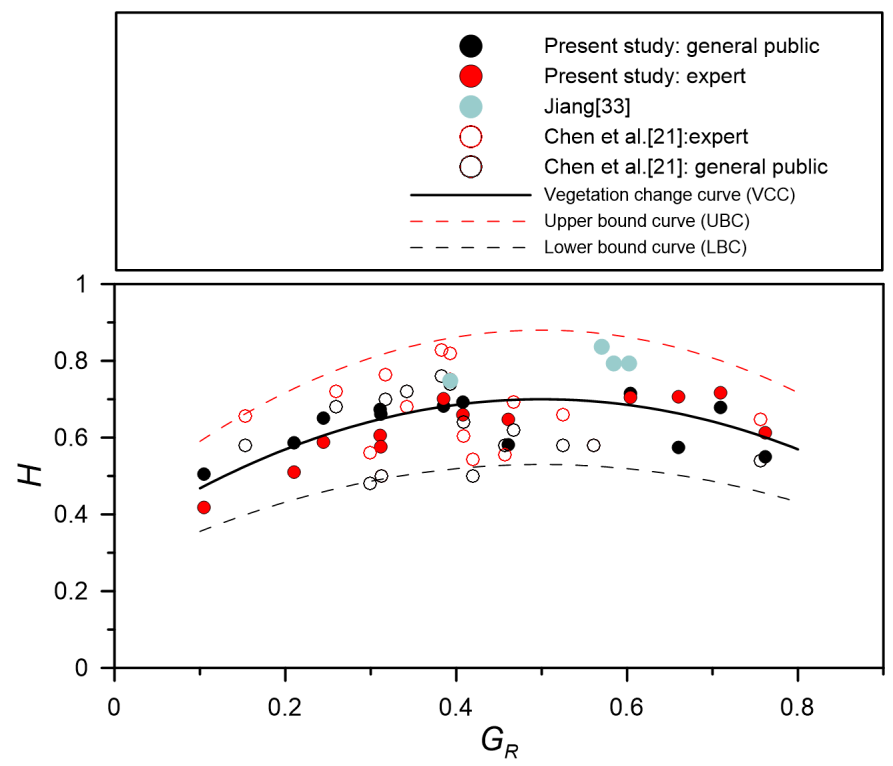

Figure 6. Relationship between the harmony $H$ and percentage of visible greenery $G_{R}$ : comparison between current and previous findings. 


\subsubsection{Visual Harmony and Visible Greenery}

The fit line between visual harmony and visible greenery based on current data (Groups C1, C2, and C3) is shown in Figure 6. The fit equation (the solid line in the figure) with the correlation coefficient of $r=0.78$ can be expressed as follows:

$$
H=-1.45\left(G_{R}-0.5\right)^{2}+0.7
$$

In Equation (5), harmony is maximum, at $H=0.7$ when $G_{R}=0.5$; that is, there is a moderate increase in the amount of vegetation. For example, when $G_{R}<0.5$, the perception of harmony increased. This equation was developed based on changes in vegetation from stream engineering under the following conditions: $0.2<G_{R}<0.8,10 \%<W_{R}<30 \%$, $I_{R}<60 \%$, and $0.1<N_{R}<1.0$. These conditions almost cover the ranges of previous studies. Thus, data from previous studies, but mostly not from vegetation variations, except [33], are scattered compared with current data. The upper and lower bounds of all data show trend similar to that in Equation (5), that is, approximately 1.25 times and 0.75 times that of Equation (5), as shown below:

$$
\begin{aligned}
& H=-1.81\left(G_{R}-0.5\right)^{2}+0.88 \text { for upper bound curve } \\
& H=-1.09\left(G_{R}-0.5\right)^{2}+0.53 \text { for lower bound curve }
\end{aligned}
$$

Equation (5) was obtained from the fit curve of vegetation changes, or VCC. The VCC (Equation (5)) is located at the centre between the upper bound (Equation (6)) and lower bound (Equation (7))) curves. The three curves were used to discuss the changes of the visual harmony and visible greenery relationship between the two bounds, the effect on the relationship of harmony with visible greenery, and visual perception, respectively.

\subsubsection{Factors Affecting the Harmony and Visible Greenery Relationship}

Harmony refers to the unity and balance of the entire landscape in the visual effect. It can be enhanced or diminished by introducing or combining similar or dissimilar landscape elements and spatial arrangements [21]. Harmony, in this study, can be affected by landscape elements such as vegetation and water amount, size, form and colour of the structure, texture or material of the structure's surface, and the spatial arrangements thereof. The effect of water amount, visual proportion of structure, and materials on the structure's surface on the relationship between harmony and visible greenery are discussed as follows.

\section{(1) Water amount}

We find that a moderate amount of vegetation can improve harmony, but excessive vegetation could be detrimental to harmony. The reason may be that excess vegetation harms the overall unity of the stream landscape at $G_{R}>50 \%$, thereby reducing harmony. Besides vegetation, water is an important softscape element in stream landscape. Water features in the literature are related to coherence or harmony of the scene [17] and it is helpful to add the sense of orderliness in a landscape [18].

Figure 7a shows that harmony varies with the percentage of visible greenery and water amount. Three fitting curves based on various values of $W_{R}: 20 \%<W_{R}<30 \%$ with $\mathrm{r}=0.85,10 \%<W_{R}<20 \%$ with $\mathrm{r}=0.65$, and $W_{R}<10 \%$ with $\mathrm{r}=0.58$, show direct proportionality between harmony and visible water, similar to $G_{R}$. For example, $H=0.65$ with $W_{R}=20-30 \%$ is higher than $H=0.55$ with $W_{R}=10-20 \%$ and $H=0.45$ with $W_{R}<10 \%$ when $G_{R}=30 \%$. The softscape elements of visible greenery and visible water may also affect each other. An image with larger visible greenery may limit the space of water and reduce $W_{R}$, while an image with smaller visible greenery may promote more $W_{R}$. We find that most images with higher visible water are at $G_{R}<50 \%$ in Figure $7 \mathrm{a}$. Generally, $W_{R}<10 \%$ is mainly distributed near the lower bound curve or $G_{R}>50 \%$, which is unfavourable to harmony. Most of the data collected show that visible water is less than $30 \%$. Two data points with $W_{R}=42 \%$-samples from the general public and experts in Image A-2 in 
Figure A1 of Appendix A-show that the value of visual harmony is smaller than visual harmony with $W_{R}=30 \%$ (Image A-13). Excessive water amount may thus destroy the balance or unity of an image and reduce harmony [21]. However, our collected data are limited to $W_{R}<30 \%$. We recommend more studies to investigate the critical value of $W_{R}$.

(2) Proportion of structure

The proportion of the structure in the image affects the harmony. Figure $7 \mathrm{~b}$ shows the relationship between visual harmony and visible greenery at various percentages of visible structure $\left(I_{R}\right)$. The values of visual harmony with $I_{R}>0.3$ are concentered between VCC and the lower bound curve, occupying $73 \%$ of the total. Visual harmony values with $I_{R}<0.3$ are mostly distributed between the upper bound curve and VCC at $G_{R}<50 \%$, occupying $78 \%$ of the total. That is, visual harmony with $I_{R}<30 \%$ is higher than that with $I_{R}>30 \%$. Thus, harmony will be low if the proportion of the structure in the image is extremely large. In visual, relatively large artificial structures in stream or river may reduce the naturalness of the landscape, affect the unity and coordination of the overall environment, and reduce the harmony.

\section{(3) Materials on the surface}

In the past, the surface of structure was often smoothed with cement. Advances in ecology and aesthetics now demands the surface of such structures to be roughened, encouraging the use of local materials, such as boulders and stones. A structure with local stone surfaces can also save cost and resources and improve the ecological function of the structure. However, the stone is conducive to plant invasion because of its porous nature and the voids between stones. Thus, the surface of the structure gradually begins to green from vegetation invasion.

The materials of structure's surface were classified into near-natural, unnatural, and other types using the index $N_{R}$, the percentage of natural material on the structure that is visible. On-site stones or boulders are commonly used natural materials in mountain stream engineering. A structure with $N_{R}>0.9$ is classified as "natural type," $N_{R}<0.1$ is an "unnatural type," and $0.1<N_{R}<0.9$ is "other." Images attributed to the unnatural type used concrete with an artificially smoothed or rough texture on the surface. Most data showing $N_{R}>0.9$ are concentrated between the upper bound curve and VCC, occupied $77 \%$ of the total, and all data near the lower bound curve show $N_{R}<0.1$. That is, most images showing natural materials on the structure's surface elicit higher harmony, while those with unnatural ones elicit lower harmony. Harmony can be regarded as visually unifying and balancing for all the hardscape elements (e.g., form, colour, texture or materials) and softscape elements (e.g., water and vegetation). Thus, engineering structures that use natural materials, such as stone revetments, are more easily integrated with the surrounding environment than materials not found in nature [21]; and it will be helpful to increase visual harmony.

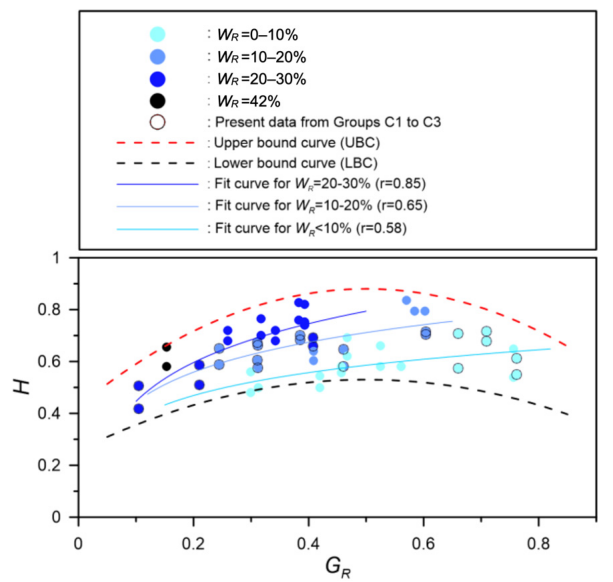

(a)

Figure 7. Cont. 


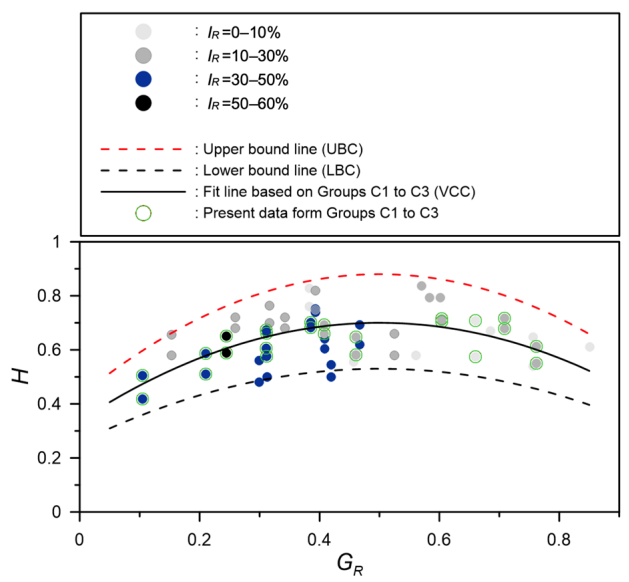

(b)

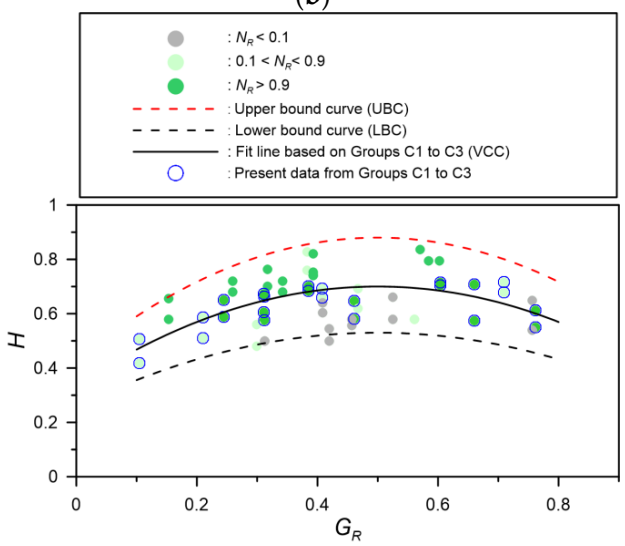

(c)

Figure 7. Relationship between harmony $H$ and percentage of visible greenery $G_{R}$ at various values of water amount, proportion of structure, and material used. (a) Various percentage of visible water $\left(W_{R}\right)$; (b) various percentage of visible structure $\left(I_{R}\right)$; (c) various percentage of natural material on structure in visibility $\left(N_{R}\right)$.

\subsection{Visual Preference}

\subsubsection{Relationship between Visual Preference and Harmony}

The visual preference associated with visual harmony for samples of the general public and experts are shown in Figure 8. Two examples from the general public and expert are not different between visual preference and $H$.

Figure 8 shows that visual harmony is highly correlated to visual preference either for present or previous studies. The variations in visual harmony were approximately equivalent to the variations in $P$; the relationship between visual preference and visual harmony can be expressed as:

$$
P=H
$$

This result implies that visual harmony is an important indicator to evaluate visual preference and this aligns with the previous findings that $P$ and $H$ are often used interchangeably [13]. Chen et al. [21] also suggested that harmony has a high weighting factor on visual preferences, and it should be seriously considered for assessment of visual quality of sediment control structures in mountain streams. When visual harmony is replaced with visual preference in Equations (5)-(7), that is, $P=H$, the middle (VCC), upper bound, and lower bound curves between visual preference and visible greenery can be determined (see Figure 9, which also shows data from current and previous findings). 


\subsubsection{Factors Affecting the Visual Preference and Visible Greenery Relationship}

Because visual preference is highly correlated to harmony, we expect similar results for visual preference in Figure 10. However, data for visible water, structure, and natural material for the relationship between visual preference and visible greenery are slightly scattered compared with the visual harmony and visible greenery relationship. Visual preference increases with increasing visible greenery $\left(G_{R}\right.$ at $\left.50 \%\right)$ but decreases when $G_{R}>50 \%$. The relation between preference and visible greenery is also affected by the visibility of water, structures, and natural material. Most data points showed that higher visual preferences between the upper bound curve and VCC, usually have the following characteristics: $0.1<W_{R}<0.3$ (72\% in Figure 10a); $I_{R}<0.3$ (70\% in Figure $\left.10 \mathrm{~b}\right)$; and $N_{R}>0.9$ (occupied 70\% in Figure 10c). Most data were close to the lower bound curve, implying lower visual preference, have excessive amount of greenery $\left(G_{R}>0.5\right)$, much less water $\left(W_{R}<0.1\right)$, excess of structures $\left(I_{R}>0.3\right.$ and $\left.G_{R}<0.5\right)$, or use of unnatural materials $\left(N_{R}<0.1\right)$. Visual preference can also be increased at $W_{R}<0.3$ and $G_{R}<0.5$.

Vegetation and water are important softscape elements in stream landscape. The common hardscape elements include the structure's surface materials, scale, and form. Harmony and visual preference can be altered by adjusting the softscape and hardscape elements, as follows: (1) setting $G_{R}<50 \%$ by managing and maintaining the vegetation on streambeds and revetments; (2) constructing, for example, a weir or groundsill, to raise the water level for $W_{R}<10 \%$; (3) using natural materials for the structures' surface, and (4) ensuring the structure is not too large $\left(I_{R}<30 \%\right)$ as seen from a viewpoint. These suggestions will be helpful in designing new stream structures in mountainous regions and in maintaining existing ones.

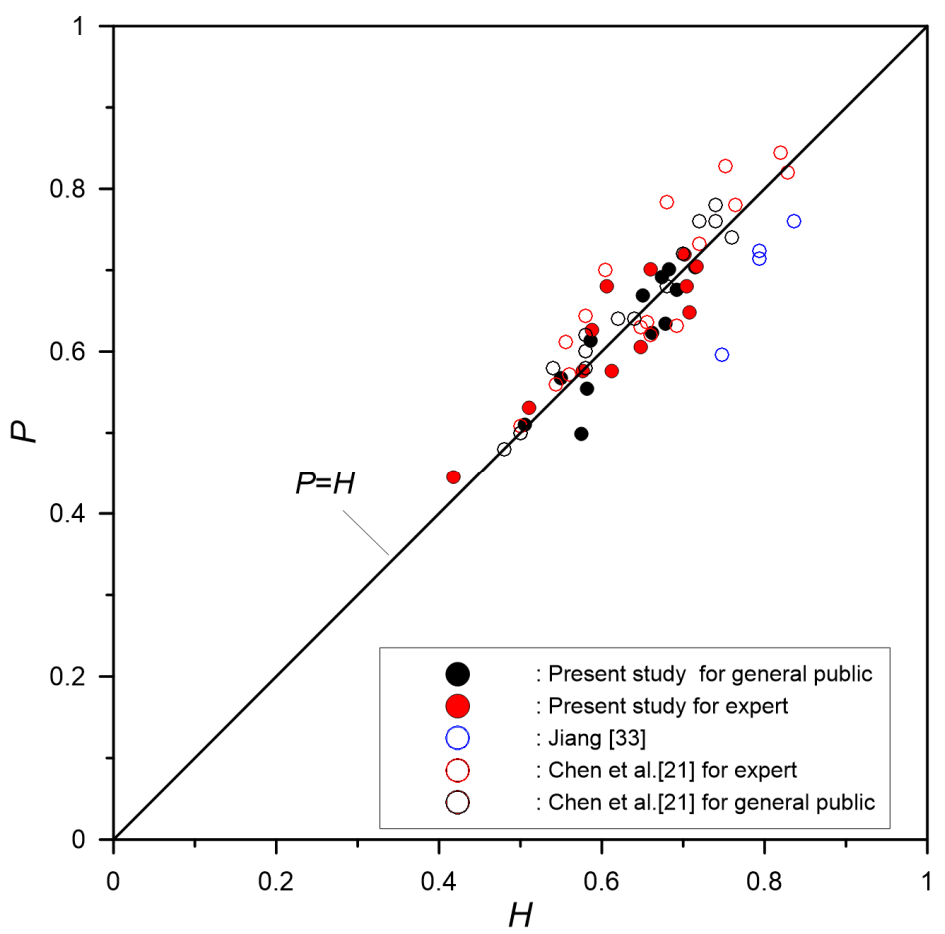

Figure 8. Visual preference $P$ and harmony $H$ : comparison between current and previous findings. 


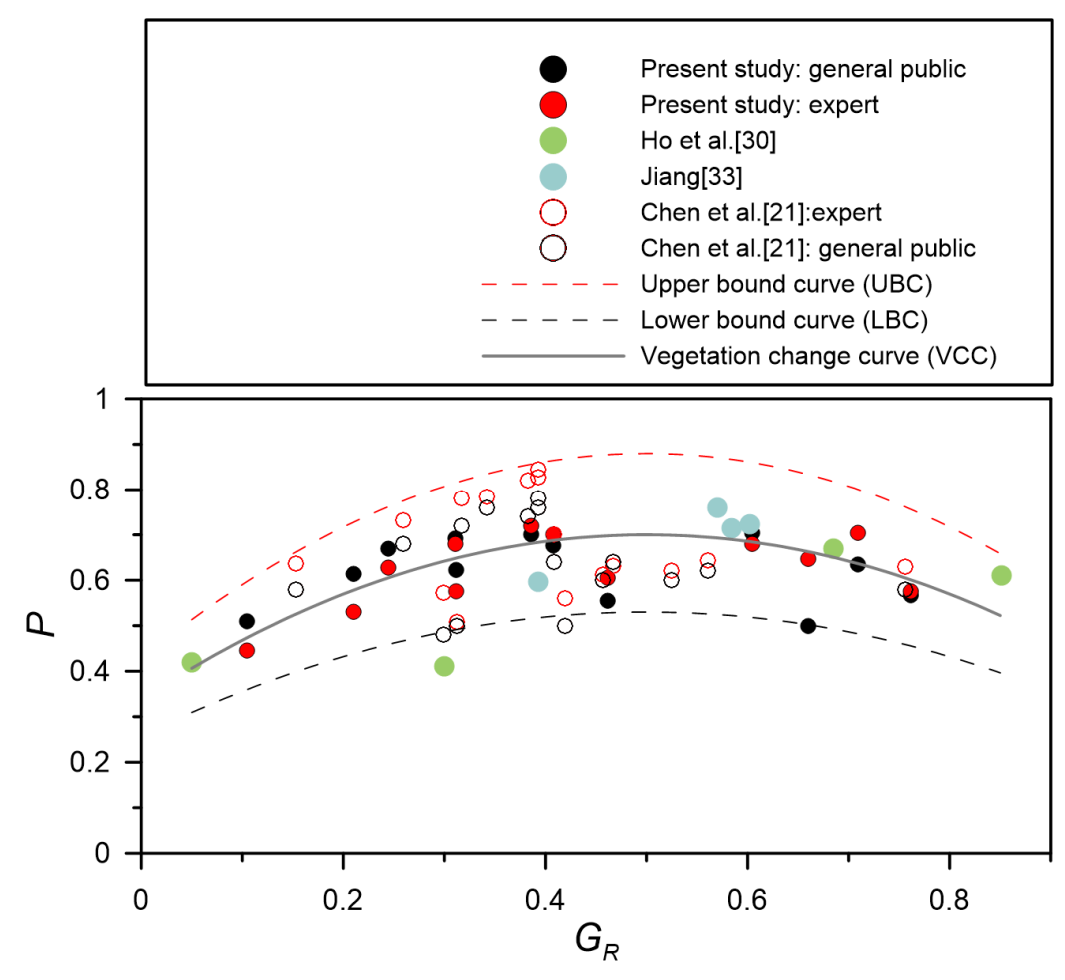

Figure 9. Visual preference $P$ and percentage of visible greenery $G_{R}$ : comparison between current and previous findings.

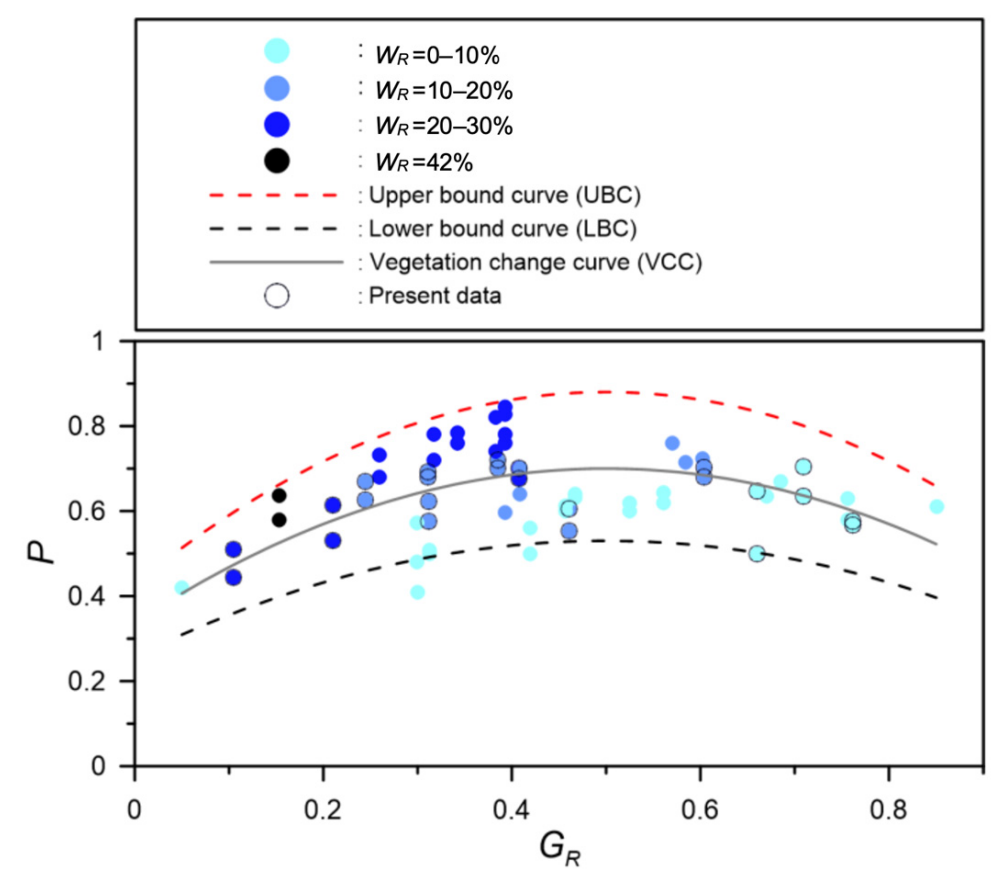

(a)

Figure 10. Cont. 


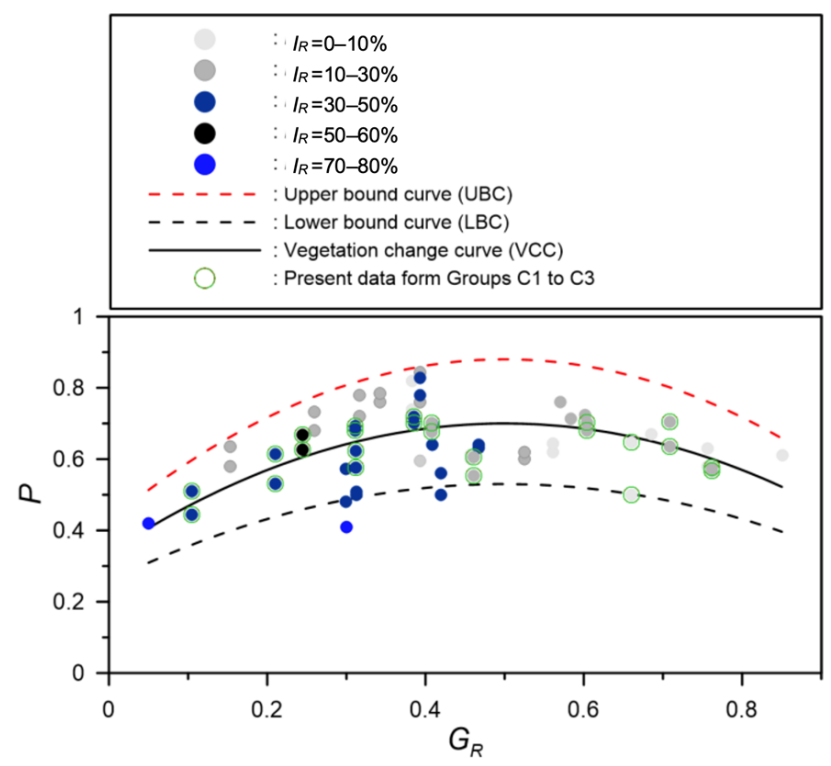

(b)

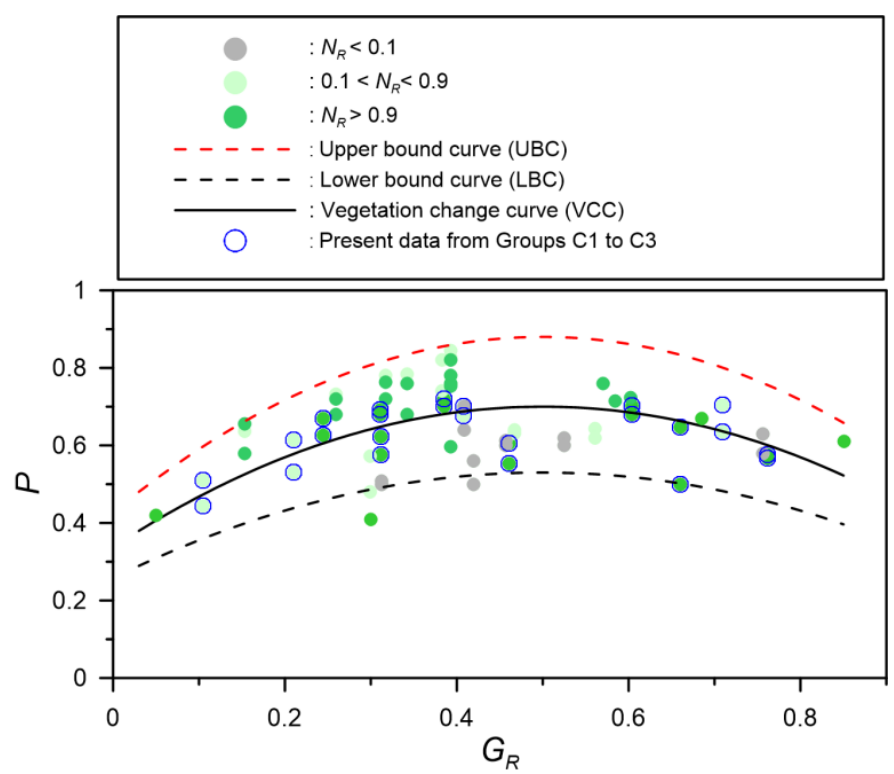

(c)

Figure 10. Visual preference $P$ and percentage of visible greenery $G_{R}$ at various values of water amount, proportion of structure, and material used. (a) Various percentages of visible water $\left(W_{R}\right)$; (b) various percentages of visible structure $\left(I_{R}\right)$; (c) various percentages of natural material on structure in visibility $\left(N_{R}\right)$.

\subsection{Model Using the Combined Physical Indicator M}

The pixels of an image in this study are composed of visible greenery amount $\left(G_{R}\right)$, water $\left(W_{R}\right)$, infrastructure $\left(I_{R}\right)$ and other visuals $\left(O_{R}\right)$. $O_{R}$ is the percentage of pixels in an image excluding $G_{R}, W_{R}$ and $I_{R}$, that is, $O_{R}=1-G_{R}-W_{R}-I_{R}$; it is mainly occupied by the sky and/or sediment (soil or rock). $N_{R} I_{R}$ is the percentage of infrastructure or the structure's surface covered by natural material. A combined physical indicator $M$ comprising all visible indicators was used to analyze the relationship between visual 
harmony (or preference) and $M$. We assume that all physical elements, $G_{R}, W_{R}, N_{R} I_{R}$, and $O_{R}$, are linearly correlated to $M$, and can be expressed as follows:

$$
M=\beta_{1} G_{R}+\beta_{2} W_{R}+\beta_{3} N_{R} I_{R}+\beta_{4} O_{R}-\varepsilon_{m}
$$

In Equation (9), $\beta_{1}, \beta_{2}, \beta_{3}$, and $\beta_{4}$ are the weighting coefficients for $G_{R}, W_{R}, N_{R} I_{R}$ and $O_{R}$, respectively. $\beta_{1}+\beta_{2}+\beta_{3}+\beta_{4}=1$. $\varepsilon_{m}$ is the modified term owing to excessive green amount $\left(G_{R}>0.5\right)$. Assume that $\varepsilon_{m}$ is linearly correlated to the term of $\left(G_{R}-0.5\right)$ and expressed by $\varepsilon_{m}=\alpha\left(G_{R}-0.5\right)$ in which $\alpha=0$ when $G_{R} \leq 0.5$. The empirical coefficients for $\beta_{1}, \beta_{2}, \beta_{3}, \beta_{4}$ and $\alpha$ were determined by trial and errors method to check the correlation between visual harmony or visual preference and $M$. With $\beta_{1}=0.45, \beta_{2}=0.25, \beta_{3}=0.2$, $\beta_{4}=0.1$, and $\alpha=0.5$ in Equation (9), we obtain:

$$
M=0.45 G_{R}+0.25 W_{R}+0.2 N_{R} I_{R}+0.1 O_{R}-\varepsilon_{m}
$$

where $\varepsilon_{m}=0.5\left(G_{R}-0.5\right)$ when $G_{R}>0.5$ and $\varepsilon_{m}=0$ when $G_{R} \leq 0.5$.

Figures 11 and 12 showed that visual harmony and visual preference are positively correlated to $M$. The fit equations between visual harmony or visual preference and $M$ with correlation coefficient $r=0.70$ and $r=0.65$, respectively, shown in the solid line in Figures 11 and 12, can be expressed as:

$$
\begin{aligned}
& H=1.815 M+0.178 \\
& P=1.716 M+0.198
\end{aligned}
$$

Two dash lines, apart from the above equations with $\pm s$ and standard deviation $s=0.095$ and 0.098 for visual harmony and preference, respectively, are also shown in Figures 11 and 12. This result implies that $M$ can be used as an indicator to evaluate visual harmony or visual preference when $G_{R}, W_{R}, N_{R}$, and $I_{R}$ are provided.

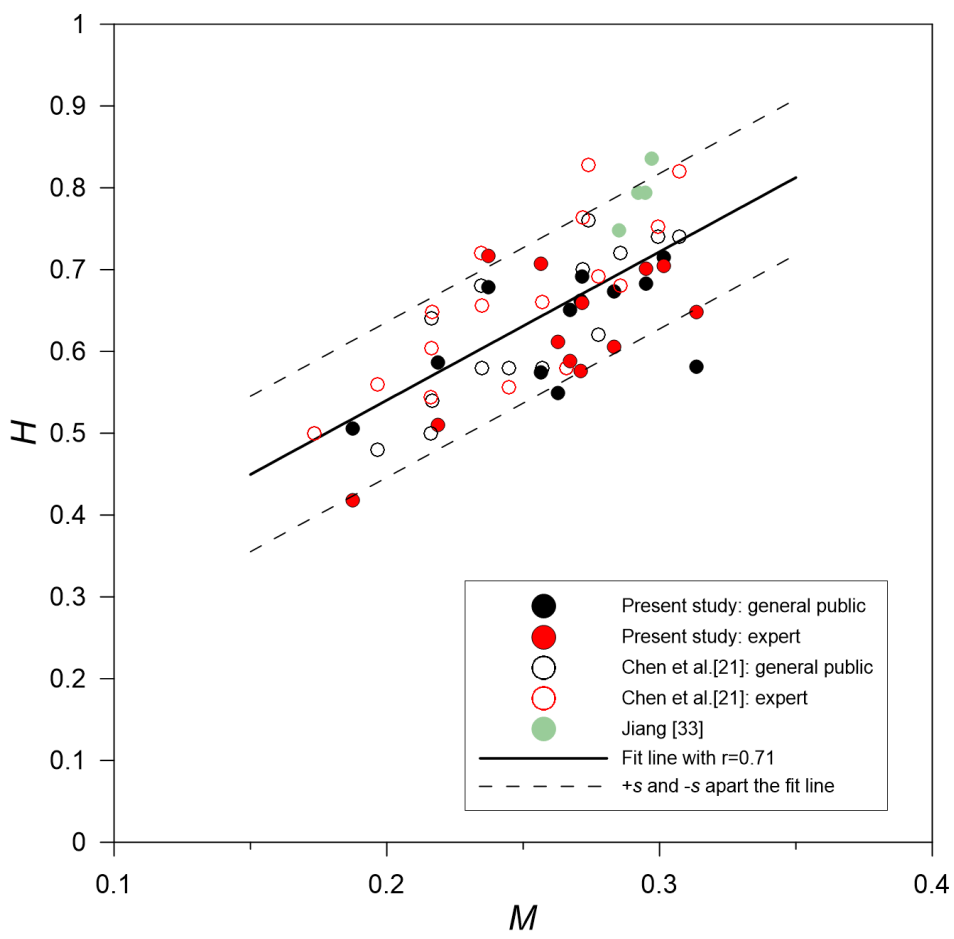

Figure 11. Relationship between harmony $H$ and the combined physical indicator $M$. Note: the figure shows a fit line (the solid line, see Equation (11)) with correlation coefficient $r=0.71$ and two dash lines apart, from the fit line with $\pm s$ and standard deviation $s=0.095$. 
A model of visual preference associated with cognitive factors (harmony, naturalness, closeness, and vividness) — a psychological based model—was proposed by [21] to evaluate the visual preference for sediment control structures in mountain streams. It was predicted using all perceived or cognitive factors. It had high correlation coefficient with $r=0.81$. Generally, this model has higher predicated results than physical-based model because visual preference is a perceived parameter. However, the physical-based model (Equations (11) and (12)) is convenient when evaluating visual harmony (or preference) because all hardscape and softscape elements, such as $G_{R}, W_{R}, N_{R}$, and $I_{R}$, can be taken more easily from a field by an image; and harmony or preference can be achieved by ensuring that all landscape elements are considered holistically [21]. Our findings could be helpful for those who design a landscape in mountainous streams with engineering structures, which can be preferred by the public or harmonious with the surrounding environment.

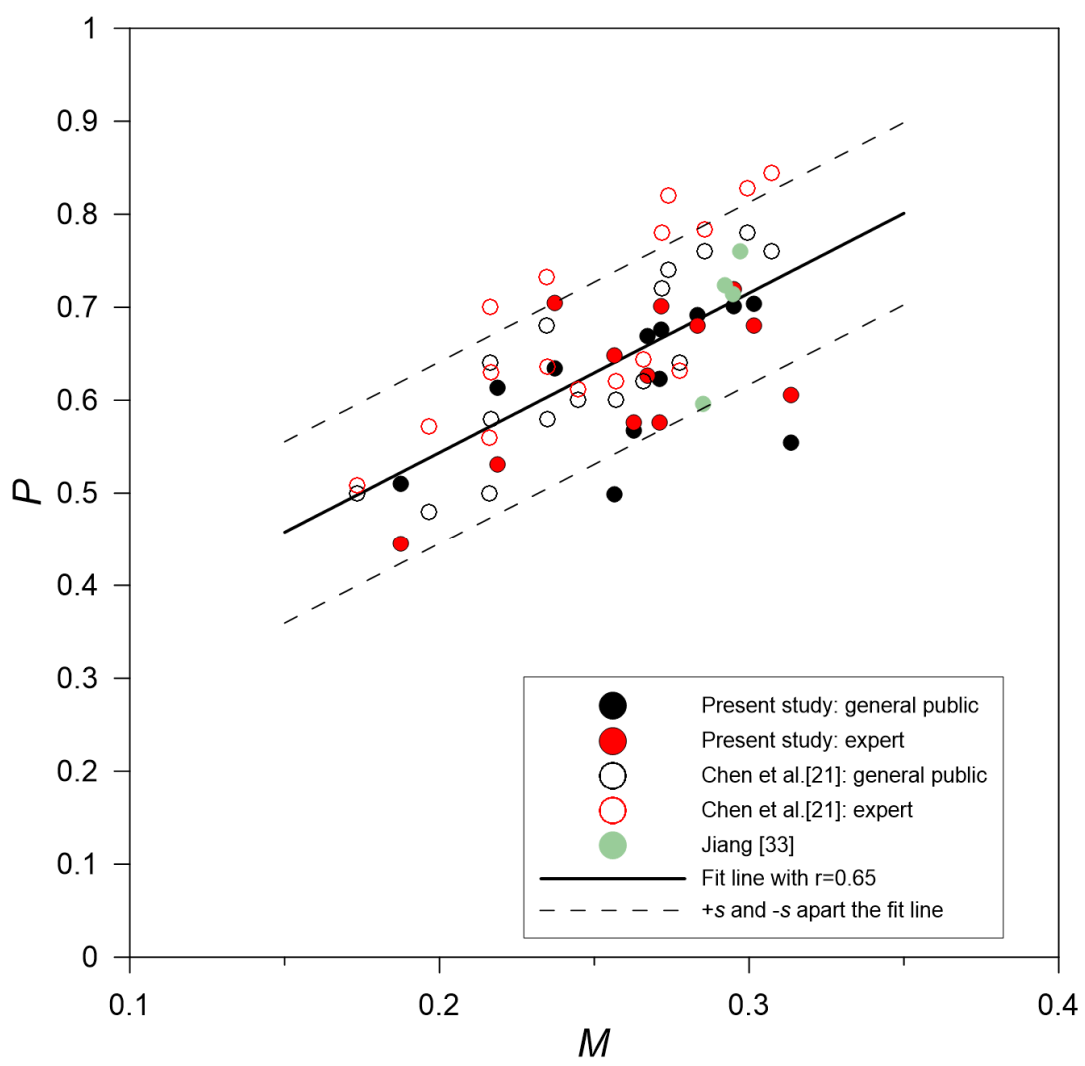

Figure 12. Relationship between visual preference $P$ and combined physical indicator $M$. Note: the figure shows the fit line (the solid line, see Equation (12)) with the correlation coefficient $r=0.65$ and two dashed lines, apart from the fit line with $\pm s$ and standard deviation $s=0.098$.

\section{Conclusions}

This study evaluated the visual harmony of engineering structures in mountain streams. The results are as follows:

- Visual harmony $H$ is highly correlated to visual preference $P$ for a landscape of stream engineering in mountainous regions. The perceived curve of vegetation change (VCC) that responds to variations of visual harmony and preference owing to vegetation changes were determined. We found that 1.25 and 0.75 times of VCC can be used to describe the upper and lower bound curves for the stream landscape.

- Vegetation invasion can improve visual quality but may decrease with excess plant growth (visible greenery $G_{R}>50 \%$ ) without management and maintenance. Both $H$ and $P$ can be improved by cleaning excess vegetation in riverbeds or riverbanks. The 
model for the relationship between $H$ (or $P$ ) and $G_{R}$ proposed herein can be used as reference for the maintenance of streams structures in mountainous regions.

- $\quad H$ and $P$ can be altered by adjusting the softscape and hardscape. Both $G_{R}$ and visible water $W_{R}$ need to be increased to improve $H$ and $P$, if $G_{R}<50 \%$. Generally, $W_{R}<10 \%$ is unfavorable to visual harmony and may reduce preference. Hardscape elements also have a positive effect if the visibility of engineering structures $\left(I_{R}\right)$ is below $30 \%$ and the proportion of natural materials on structure $\left(N_{R}\right)$ is over 0.9 .

- The model of $H$ (or $P$ ) and the combined physical indicator $M$ was developed. This model is composed of visible indicators, $G_{R}, W_{R}, N_{R}$, and $I_{R}$, that can be taken by an image. It is convenient for the designer or manager to determine a stream landscape with engineering structures, which can be preferred by the public or harmonious with the surrounding environment. Results of this study could improve the visual beauty for stream engineering and environment design.

- Images analysed in this study were limited to a landscape with engineering structures in Taiwan's mountain streams. The model of visual harmony (or preference) was developed under the following conditions: stream width of $5 \mathrm{~m}$ to $20 \mathrm{~m}$; stream gradient of 5-40\%; an image showing a view with both sides of river visible at an accessible height; and the physical visual indicators in the ranges of $5 \%<G_{R}<85 \%$, $W_{R}<42 \%, I_{R}<80 \%$, and $N_{R}<1.0$. However, other factors such as color (seasonal changes in vegetation) and arrangement of landscape elements, such as water form and landform, were not included and should be explored in future studies.

Author Contributions: Conceptualization, J.-C.C. and S.-C.C.; methodology, J.-C.C.; formal analysis, J.-C.C. and C.-L.H.; resources, S.-C.C. and S.S.T.; writing and editing, J.-C.C., S.-C.C. and S.S.T.; funding acquisition, S.-C.C. All authors have read and agreed to the published version of the manuscript.

Funding: This research was funded by the Ministry of Science and Technology, Taiwan, under grant MOST 109-2327-B-005-004, Soil and Water Conservation Bureau, Taiwan, Grant Number 108 SWCB-10.1-C-01-06-001(6), and Sanming City Science and Technology Bureau, China, Grant Number 2020-S-81.

Data Availability Statement: The datasets generated during and/or analysed during the current study are available from the corresponding author on reasonable request.

Acknowledgments: We appreciate the image processing assistance of graduate students at Huafan University and National Chung Hsing University.

Conflicts of Interest: The authors declare no conflict of interest. The funders had no role in the design of the study; in the collection, analyses, or interpretation of data; in the writing of the manuscript, or in the decision to publish the results.

\section{Appendix A}

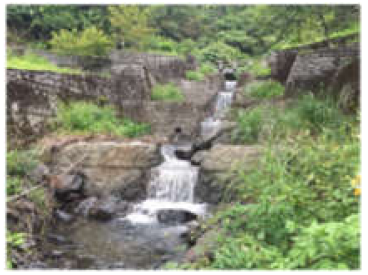

A - 1

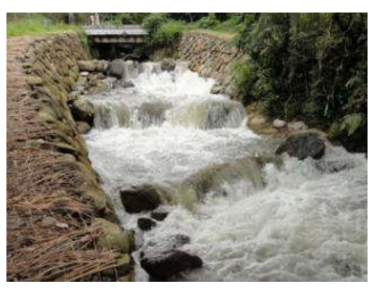

A-2

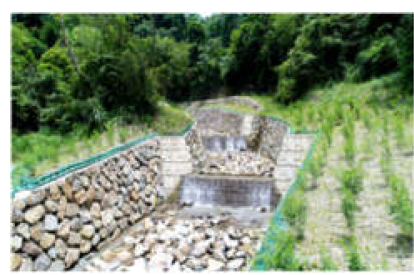

A-3

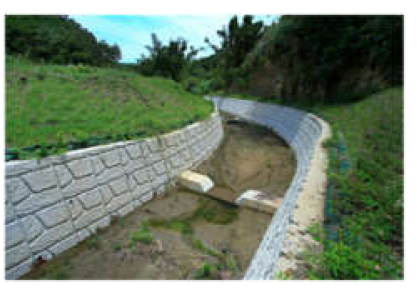

A-4

Figure A1. Cont. 


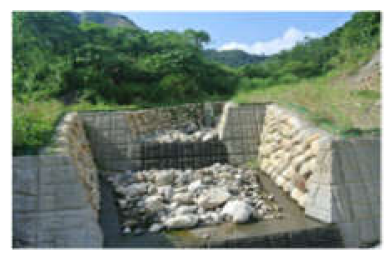

A-5

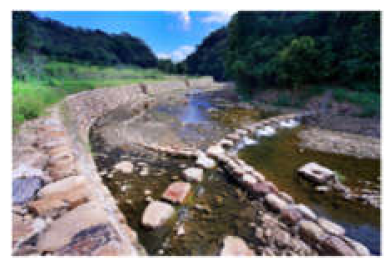

A-9

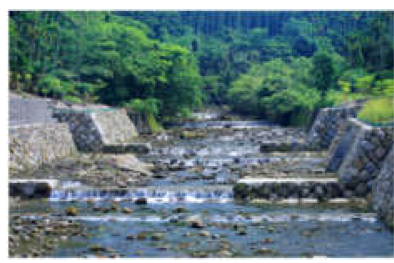

A -13

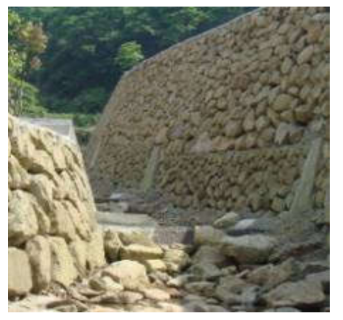

A-17

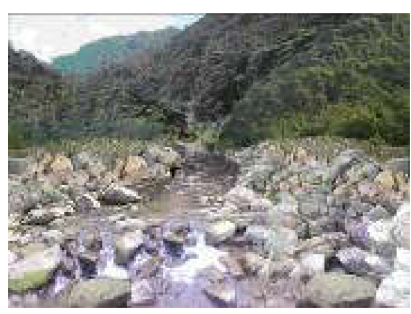

A-21
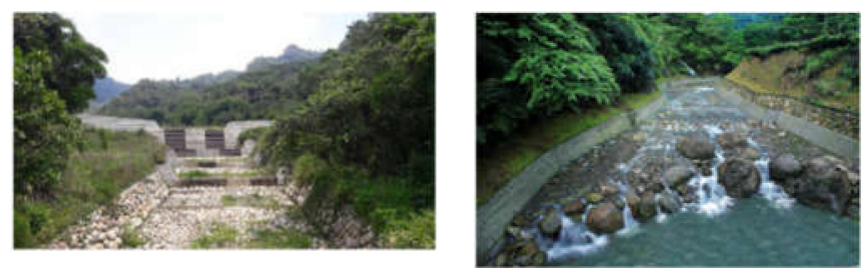

A-7

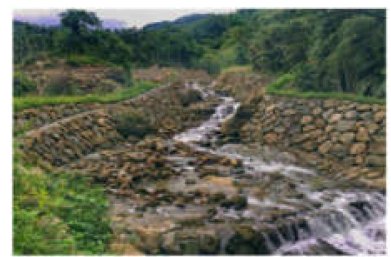

A-10

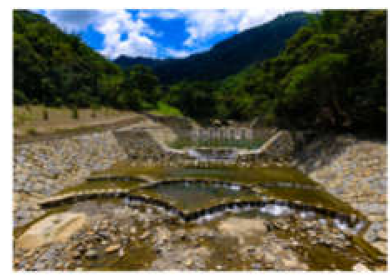

A-14

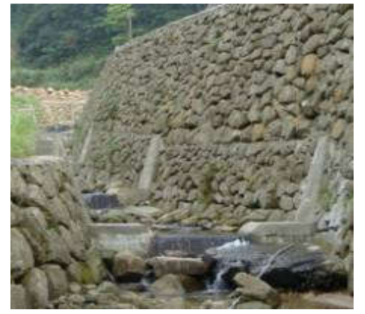

\section{A-18}

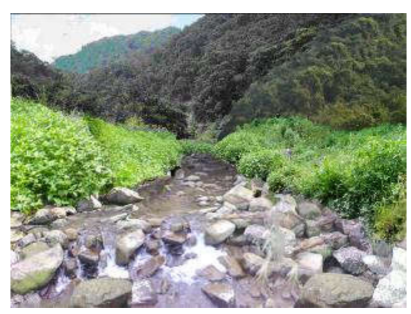

A-22

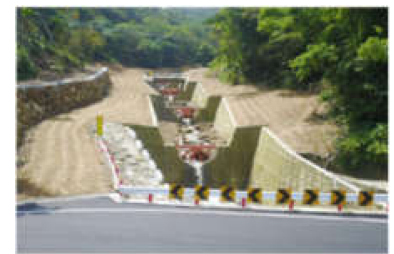

A-11

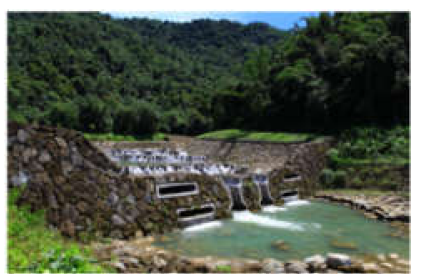

A-15



A-19

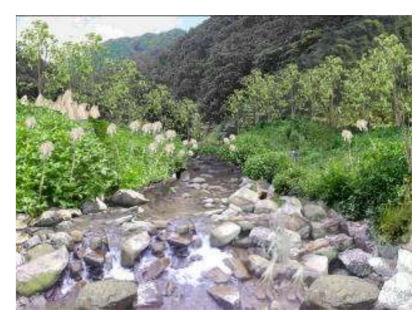

A-23

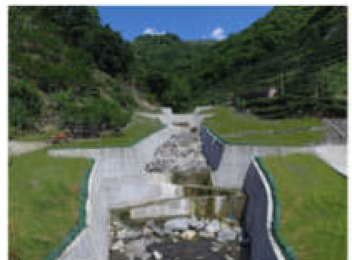

A-8

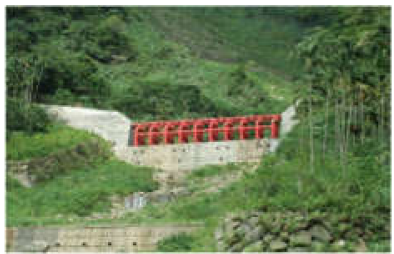

A-12

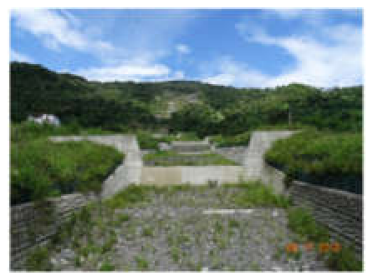

A-16

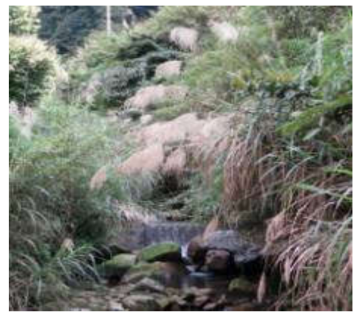

A-20

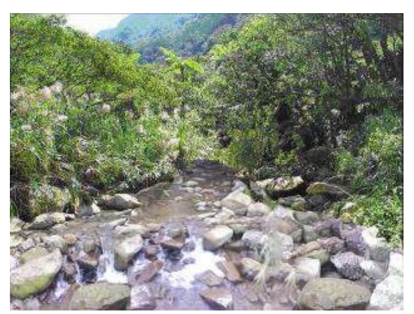

A-24

Figure A1. Images collected from previous studies on mountain streams in Taiwan. Note. Images A-1 to A-16 show various sediment control structures at different locations from [21]; Images A-17 to A-20 [30] and Images A-21 to A-24 [33] are from revetments with vegetation invasion at a fixed location.

\section{References}

1. Wu, H.-L.; Feng, Z.-y. Ecological engineering methods for soil and water conservation in Taiwan. Ecol. Eng. 2006, 28, 333-344. [CrossRef]

2. Zuo, Q.T.; Zhang, Y.; Lin, P. Index system and quantification method for human-water harmony. J. Hydraul. Eng. 2008, 39, 440-447.

3. Ding, Y.; Tang, D.; Dai, H.; Wei, Y. Human-Water Harmony Index: A New Approach to Assess the Human Water Relationship. Water Resour. Manag. 2014, 28, 1061-1077. [CrossRef] 
4. Zuo, Q.; Li, W.; Zhao, H.; Ma, J.; Han, C.; Luo, Z. A Harmony-Based Approach for Assessing and Regulating Human-Water Relationships: A Case Study of Henan Province in China. Water 2021, 13, 32. [CrossRef]

5. Zingraff-Hamed, A.; Bonnefond, M.; Bonthoux, S.; Legay, N.; Greulich, S.; Robert, A.; Rotgé, V.; Serrano, J.; Cao, Y.; Bala, R.; et al. Human-River Encounter Sites: Looking for Harmony between Humans and Nature in Cities. Sustainability 2021, $13,2864$. [CrossRef]

6. Ćosić-Flajsig, G.; Vučković, I.; Karleuša, B. An Innovative Holistic Approach to an E-flow Assessment Model. Civ. Eng. J. 2020, 6, 2188-2202. [CrossRef]

7. Ou, L.-C.; Luo, M.R. A colour harmony model for two-colour combinations. Color Res. Appl. 2006, 31, 191-204. [CrossRef]

8. Schloss, K.B.; Palmer, S.E. Aesthetic response to color combinations: Preference, harmony, and similarity. Atten. Percept. Psychophys. 2011, 73, 551-571. [CrossRef]

9. Ebigbagha, S. Achieving Harmonious Colour Relationship in Art/Design: Towards a Mathematical Model. Afr. Res. Rev. 2015, 9, 157. [CrossRef]

10. Rahnama, M.R.; Khavari, F. Analytical Study of Color Harmony in Urban Spaces of Mashhad, Northeast Iran. Int. J. Sci. Eng. Res. 2014, 5, 756-762.

11. Zhu, X.; Tan, S. Degree of Harmony of Urban Land Use and Economic Development: Case Study of Wuhan Metropolitan Area. J. Sustain. Dev. 2014, 7, 139. [CrossRef]

12. Judd, D.B.; Wyszecki, G. Color in Business, Science, and Industry, 3rd ed.; John Wiley \& Sons, Ltd: New York, NY, USA, 1975; Volume 42, p. 576.

13. Palmer, S.E.; Schloss, K.B.; Sammartino, J. Visual Aesthetics and Human Preference. Annu. Rev. Psychol. 2013, 64, 77-107. [CrossRef]

14. United States Forest Service. Landscape Aesthetics: A Handbook for Scenery Management; U.S. Department of Agriculture, Forest Service: Washington, DC, USA, 1995.

15. Bell, S. Landscape: Pattern, Perception and Process; Routledge: London, UK, 2012.

16. Tveit, M.; Ode, Å.; Fry, G. Key concepts in a framework for analysing visual landscape character. Landsc. Res. 2006, 31, 229-255. [CrossRef]

17. Litton, R.B. Water and Landscape: An Aesthetic Overview of the Role of Water in the Landscape; Water Information Center: New York, NY, USA, 1974.

18. Kaplan, R. Down by the Riverside: Informational Factors in Waterscape Preference; USDA Forest Service General Technical Report: Washington, DC, USA, 1977; pp. 285-289.

19. Mansvelt, J.; Kuiper, J.J. Criteria for the humanity realm: Psychology and physiognomy and cultural heritage. In Checklist for Sustainable Landscape Management; Elsevier: London, UK, 1999.

20. Kuiper, J. Landscape quality based upon diversity, coherence and continuity: Landscape planning at different planning-levels in the River area of The Netherlands. Landsc. Urban Plan 1998, 43, 91-104. [CrossRef]

21. Chen, J.-C.; Cheng, C.-Y.; Huang, C.-L.; Chen, S.-C. Assessment of the Visual Quality of Sediment Control Structures in Mountain Streams. Water 2020, 12, 3116. [CrossRef]

22. Memari, S.; Pazhouhanfar, M. Role of Kaplan' Preference Matrix in the Assessment of Building façade, Case of Gorgan, Iran. Arman. Archit. Urban Dev. 2018, 10, 13-25.

23. Junker Koehler, B.; Buchecker, M. Aesthetic Preferences Versus Ecological Objectives in River Restorations. Landsc. Urban Plan. 2008, 85, 141-154. [CrossRef]

24. Stewart, W.; Larkin, K.; Orland, B.; Anderson, D. Boater preferences for beach characteristics downstream from Glen Canyon Dam, Arizona. J. Environ. Manag. 2003, 69, 201-211. [CrossRef]

25. Arnberger, A.; Eder, R.; Preiner, S.; Hein, T.; Nopp-Mayr, U. Landscape Preferences of Visitors to the Danube Floodplains National Park, Vienna. Water 2021, 13, 2178. [CrossRef]

26. Piégay, H.; Gregory, K.; Bondarev, V.; Chin, A.; Dahlstrom, N.; Elosegi, A.; Gregory, S.; Joshi, V.; Mutz, M.; Rinaldi, M.; et al. Public Perception as a Barrier to Introducing Wood in Rivers for Restoration Purposes. Environ. Manag. 2005, 36, 665-674. [CrossRef]

27. Chin, A.; Daniels, M.D.; Urban, M.A.; Piégay, H.; Gregory, K.J.; Bigler, W.; Butt, A.Z.; Grable, J.L.; Gregory, S.V.; Lafrenz, M.; et al. Perceptions of wood in rivers and challenges for stream restoration in the United States. Env. Manag. 2008, 41, 893-903. [CrossRef] [PubMed]

28. Wilson, M.I.; Robertson, L.D.; Daly, M.; Walton, S.A. Effects of visual cues on assessment of water quality. J. Environ. Psychol. 1995, 15, 53-63. [CrossRef]

29. Peng, S.-H.; Han, K.-T. Assessment of Aesthetic Quality on Soil and Water Conservation Engineering Using the Scenic Beauty Estimation Method. Water 2018, 10, 407. [CrossRef]

30. Ho, L.-C.; Chen, J.-C.; Chang, C.-Y. Changes in the visual preference after stream remediation using an image power spectrum: Stone revetment construction in the Nan-Shi-Ken stream, Taiwan. Ecol. Eng. 2014, 71, 426-431. [CrossRef]

31. Kaplan, R.; Kaplan, S. The Experience of Nature: A Psychological Perspective; Cambridge University Press: New York, NY, USA, 1989; p. 340.

32. Ode, Å.; Fry, G.; Tveit, M.S.; Messager, P.; Miller, D. Indicators of perceived naturalness as drivers of landscape preference. J. Environ. Manag. 2009, 90, 375-383. [CrossRef]

33. Jiang, J.-G. Visual Preference Assessment on Streams; Huafan University: New Taipei City, Taiwan, 2016. 